\title{
Transforming Microfinance Institutions: What about the poorest in Africa?
}

\author{
Nihel Halouani ${ }^{1}$, Prof Younes Boujelbene ${ }^{2}$ \\ ${ }^{I}$ PhD student in Methods of Accounting and Finance, Sfax University, Tunisia. \\ ${ }^{2}$ Economics Professor, Sfax University, Tunisia
}

\begin{abstract}
In this paper we try to identify if the transformation of MFIs is associated with the "mission drift"? Specifically, considering that commercialization is characterized by sustainability, competition, and regulation, we evaluate its effect on the average size of loans provided and on the percentage of women borrowers. The empirical study is based on the OLS method from 96 MFIs operating in 22 African countries in 2005-2008, to study the impact of commercialization of MFIs on the average loan size and the percentage of women borrowers by groups of clients served. The results indicate that competition favor targeting the poorest and increase significantly access to cheaper and better microfinance services particularly for women. Whereas, viability is in favor of the mission drift of the MFIs no matter what the category of served clientele is. Finally, regulated MFIs lend increasingly fewer loans to women borrowers and hence deviate from their mission of serving the poor clients.
\end{abstract}

Keywords: Microfinance, Commercialization, Competition, Outreach, women.

\section{Introduction}

Originally, microfinance is a financial service adapted for poor people and renowned for its ability to reach out to women and enhance their welfare. However, the increase in the number transformed MFIs alert the accessibility of the poor people to of MFIs. For these reasons, we aim to identify in this article the impact of the commercialization on the risk of excluding the poor and hence the risk of mission drift.

The African context is characterized by the prevalence non-profit-making and social vocation MFIs, particularly NGO (non-governmental organizations), which explains the contribution of these MFIs to the reduction of poverty. This calls into question the success of the commercial approach in Africa. In this context, the cases of transformations differ from a country to another. We found successful cases of transformations where there is no mission drift of the MFIs. Indeed, the cases of BUUSAA GONOFAA in Ethiopia show how an MFI, by enhancing its indicators of efficiency and profitability, manages, today, to conciliate the economic profitability through serving rural isolated and marginal populations (SOS FAIM, 2007) in addition to the case of Latin American MFIs which follow, mainly, a commercial approach without straying from their original social mission. In this framework, Christen (2001) justifies the increase of the level of credits resulting from the commercialization of MFIs by the strategy's choice; the period of entrance (entry) to the market or the natural evolution of the target group. Likewise, Felloni and Seibel (2003) show that the commercialization of banks in Filipina (Philippine) led to a slight increase of the granted loans with no major drifts in their mission.

However, realizing the autonomy of the MFI without depending on direct and continuous contributions of the funders may be a direct cause of the marginalization of the poor from the services offered by the sector of microfinance through offering the high-end segment of a market. Particularly, collecting the savings involves significant initial costs in addition to the competition with the largest and oldest banks beside the cultural change of the transformed profit-making MFIs generate very high costs and may lead to a change in the served clientele. In this framework, the transformation of the Bolivian NGO "PRODEM" into "BancoSol" in 1992 was the origin of mission drift in this MFI (Rhyne, 1998). Similarly, the Mexican bank "Compartamos" introduced a part of its capital to stock exchange pushing the shareholders to sell their shares and so realize important financial surplus.

The question raised at this level which seems to be at the origin of a frequent debate deals with the impact of commercialization on the targeting of the poor. Our study differs from existing literatures in the decomposing the commercialization into three sub-components namely; viability, regulation and competition. Furthermore, we classified the served clients according to the average loan size and also to poorest women to identify the most vulnerable category facing the aforesaid components.

Finally, our study is specifically oriented toward the mission drift question which can happen when the MFI stops serving the segment of poor customers by choosing a commercial approach. (Woller, Dunford, and Woodworth, on 1999 and Woller, on 2002).

In this paper, we assess the impact of commercialization on the inclusion of the poor using a sample of 96 MFIs in 22 countries of Africa in the period from 2005 to 2008. Indeed, the microfinance in Africa has widely 
contributed to the reduction of poverty and the inclusion of the poor in the financial sector through realizing the objectives of the millenniums, which constitutes the original objective of microfinance. But is it important to ask the question of the continuity of this positive contribution with the transformation of the MFIs? This question is treated by a set of works of literature, given its importance on the economic and social plan. (McIntosh and Wydick, on 2005; Olivares-Polanco, on 2005; Hermes and al., 2011 and Ly, on 2009; 2012).

Our paper is organized as the following: First of all, we begin with a brief review of the literature speaking about the commercial approach and the relationship between the commercialization and the inclusion of the poor. Then, we identify the factors of commercialization and we present our assumptions. Later, we introduce the employed methodology which is based on an econometric model based on the ordinary least squares (OLS) on STATA to study the impact of the commercialization of the MFIs on the average loan size and the percentage of women borrowers by group of served population. We present afterward the descriptive statistics as well as the results of our estimations which indicate that competition favor targeting the poorest and increase significantly access to cheaper and better microfinance services particularly for women. Whereas, viability is in favor of the mission drift of the MFIs no matter what the category of served clientele is. Finally, regulated MFIs lend increasingly fewer loans to women borrowers and hence deviate from their mission of serving the poor clients.

The remainder of this paper proceeds as follows: In section 2, we present the commercial approach. Section 3 presents the relation between commercialization and the inclusion of the poor as well as our hypotheses of research. The fourth section describes our sample and presents our methodology of research. The section 5 presents the results. Finally, in section 6 we expose our conclusion.

\section{Commercial approach}

Originally, the sector of microfinance put the emphasis on the social and economic outreach of the clients without giving importance to industrial sustainability (Labie and Mees,2005). However, the results are not as expected despite the volume of subsidies granted to the institutions in question which leads us to question the efficiency of the subsided approach (Armendariz de Aghion and Morduch, 2005). This leads contributors to choose the commercial approach in order to fill up these deficiencies.

The commercialization of an MFI expresses its will to evolve into a more viable organism, ruled by legislations and put under the pressure of competition, it supposes the research for the financial sustainability (Couchoro, 2011 and Hermes and al., 2011). Thus, the commercial approach is based on three key principles: Viability, Competition and Regulation. (Christen, 2001)

The first characteristic of the MFIs opting for the commercial approach is the realization of their financial autonomy. In this respect, Fernando (2004) dealt with 39 cases of micro-financial NGOs' transformation into micro-financial private companies. He finds that most transformations are accompanied by an improvement of the viability of the MFIs (Bancosol in 1992, Banco ADEMI in 1998, MIBANCO in 1998). Moreover, Christen, (2001) finds that in Latin America the MFIs which adopted a commercial approach showed a high profitability which could even exceed that of the commercial banks. On another hand, Ly (2012) finds that for certain NGOs, their transformation into a commercial entity is considered as the only way to attain selfsufficiency and profitability. However, it shows that as the NGOs are engaged in commercial businesses, they must show that the conflicts with the primary social objectives are reduced to the least to ensure that the support of the funders and the tax exemptions remains justified.

The second characteristic of the commercial approach is the competition. Indeed, once the MFIs are engaged in managing their business on a commercial basis, the competition quickly becomes a characteristic of the environment in which the MFIs operates. Indeed, the entry to the logic of the profit-making purpose obliges the MFIs to change the pricing of their outputs and their servicing mechanism in order to increase their share of the market and compete to serve a common target.

Finally, the regulation is a fundamental condition for the migration from a subsidized approach towards a commercial approach, as far as it allows to propose a wide range of adapted financial services and support the development of the sector.

\section{Commercialization and poor inclusion}

The risk of the exclusion of the poor from the MFIs which is similar to the problem of the mission drift is related to several factors, particularly in the research of the financial autonomy, the solicitation of authority's consent and the competition's pressure as well. In this context, the proxy of average balance per borrower is the most commonly used indicator in measuring the degree of MFI's targeting of the poorest population or the depth of its social outreach (Bhatt and Tang, 2001; Schreiner, 2002; Cull and al, 2007; Mersland and Strôm, 2009). In the same context, the mission drift appears when the size of the average loan increases, which indicate that the MFIs changed their targeted clientele by presenting their services to a richer segment capable of taking bigger loans and yet reducing the risk of no-refund (Mersland and Strôm). The social outreach of the MFIs may also be 
associated with the intense targeting of women in priority (Dowala and Barua, 2006). In fact, women are perceived as an especially vulnerable group, the general understanding that women are taking on the financial responsibility for family and household promised a greater development impact on a collective level. (ADA, 2007)

In this paper we are using the average loan size and the percentage of woman borrowers to measure the social outreach given that these indicators explain efficiently the quality of the target clients and so their attitudes toward an increase in the granted loans. (Cull and al.,2007)

\subsection{Viability}

\section{Components of MFIs' commercialization}

The transformation of an NGO into a commercial entity requires the financial autonomy. In fact, when we take on the loan size as a tool for the measurement of poverty level, data indicate that the method of group loans, adapted to the poor's needs, becomes a heavy burden on rich clients who are capable of investing in big businesses. In this context, Hatarska (2005) and Mersland and Strôm (2009) sees that the viability of the MFIs leads to mission drift.

Thus, certain critics brought to the MFIs fear that these institutions put more focus on profits at the expense of the outreach of poor clients under the argument that high profits result in a higher outreach. As a matter of fact, the following assumptions are founded:

\section{H1: there is a mission drift risk in viable MFIs.}

\subsection{Competition}

MFIs cannot be studied separately since they are part of the set of the financial sector of their operating zone.

\section{- Competition and outreach}

The results of the theoretic analysis suggest that the impact of competition on the social outreach is ambiguous. In this respect, two contrary points of view are processed in literature; the first one, supported by Motta (2004) and Cull and al (2009), stipulates that the competitive environment is favorable for the development of the sector of microfinance and the inclusion of the poor particularly of the women. In fact, the competition may prompt the MFIs to reduce the costs and enhance the efficiency of their transactions through improving the quality of their services in order to guarantee the loyalty of their clients. The second point of view foresees that if the increasing competition is associated with successive failures, the MFIs prefer to be engaged in more cautious credits intended for borrowers that are considered as more secure and profitable. This may decrease the outreach given that the loans granted to unexploited markets are generally seen as more risked and costly (Olivares-Polanco, 2005; Hermes and al, 2011). In this respect, McIntosh and Wydick, (2005) developed a theoretical model describing how rough competition between non-profit-making institutions may lead to a mission drift. Christen (2011), as well, foresees that the structural changes that take place due to the transformation of the MFIs in order to increase their shares of the market, can be at the origin of a mission drift due to the over debts of the clients which may lead to the degradation of the stakeholders' portfolio present on the market, which is the case of certain Bolivian MFIs.

\section{- Competition measures}

In order to determine the impact of competition on the MFIs' outreach, we must provide an adequate measurement for the competition.

The competition measurement, used in our study, is frequently applied in the banking sector and referred to as the method of "Lerner index" (Fernândez de Guevara and al, 2007 and Maudos and Fernândez de Guevara).

Lerner index (L), examines the difference between the market price (P) and the marginal production cost within the company (MC) and thus estimate the market power of the MFIs. The index varies between a maximum of 1 and a minimum of 0 with a value near to 1 wherein $\mathbf{L}=1$ indicates that the level of competition is low. However, $\mathbf{L}=0$ (wherein $\mathbf{P}=\mathbf{M C}$ ) indicates that the level of competition is very high (Hermes. $\mathrm{N}$ and al, 2011).

Lerner index $(\mathbf{L})$ is measured as follows:

$\boldsymbol{L}=\frac{\mathbf{P}-\mathbf{M C}}{\mathbf{P}}$

Where $\boldsymbol{L}$ is Lerner index, $\boldsymbol{P}$ is the market price and $\boldsymbol{M C}$ is the total marginal cost. In order to adapt the measures of this index to the circumstances of the MFIs, we must follow the approach of Maudos and Fernândezde Guevara, 2004; Fernândez de Guevara and al, 2007 and Hermes. N and al, 2011, wherein the market prices are calculated by estimating the average income of banking output by the following ratio:

$$
\boldsymbol{P}=\frac{\text { Total operating revenues }}{\text { Total assets }}
$$

The total operating revenue is the sum of interest revenues and the operating revenues (Hermes. $\mathrm{N}$ and al, 2011). The measurement of the marginal costs obtained through the derivative of the following function (cost standard translog): 


$$
\begin{aligned}
& \ln \mathbf{C}_{\mathrm{it}}=\alpha_{0}+\alpha_{1} \ln \mathrm{y}_{\mathrm{it}}+\frac{1}{2} \alpha_{2}\left(\ln \mathrm{y}_{\mathrm{it}}\right)^{2}+\sum_{j=1}^{2} \beta_{\mathrm{j}} \ln \mathrm{w}_{\mathrm{ijt}}+\sum_{j=1}^{2} \frac{1}{2} \beta_{\mathrm{j}}\left(\ln \mathrm{w}_{\mathrm{ijt}}\right)^{2}+\sum_{j=1}^{2} \gamma_{\mathrm{j}} \ln \mathrm{y}_{\mathrm{it}} \ln \mathrm{w}_{\mathrm{ijt}}+ \\
& j<\text { kyjklnwijtlnwikt }+\delta 1 \text { trend }+12 \delta 2 \text { trend } 2+\delta 3 \ln \text { yittrend }+j=12 \eta j \log \text { wijttrend }+ \text { cit } \quad \text { (3) }
\end{aligned}
$$

Where $(\boldsymbol{C})$ is the total output cost of the MFI $i$, MFI at year $\mathrm{t}$; it is estimated by the sum of the financial costs and the operating costs of the MFIs. (y) is the explicative variable representing the output value (production value) and $\left(\mathbf{w}_{\mathbf{j}}\right)$ refers to the different prices of the inputs. We employed the $\log$ for all variables.

The measurement of the production output (y) is estimated by the overall of the assets.

The price of the output factors $\left(\mathbf{w}_{\mathfrak{j}}\right)$ are explained by two entries:

- $\quad\left(\boldsymbol{w}_{\mathbf{1}}\right)=$ labor cost: [staff expenses / number of employees]

- $\quad\left(\boldsymbol{w}_{2}\right)=$ cost of physical capital: [(operational expenses - staff expenses $) /$ net fixed assets]

We estimate the cost function on the equation (3) based on the method panel data.

\section{"Insert table 1"}

The equation enables us to identify the chronologic changes within a temporal trend variable (trend) as well. After calculating (C), we can measure the marginal cost (MC) by the first derivative of the cost function relative to $\left(\operatorname{lny}_{\mathrm{it}}\right)$ :

$$
\mathrm{MC}=\left(\frac{C_{i t}}{y_{i t}}\right)\left[\alpha_{1}+\alpha_{2} \ln y_{i t}+\sum_{j=1}^{2} \gamma_{j} \ln w_{i j t}+\delta_{3} \text { trend }\right]
$$

If $\mathbf{P}=\mathbf{M C}$, Lerner index is null; the company has no market power. The competition is high. A Lerner index close to 1 refers to a weak competition at the level of the price; the company exercises a market power (Hermes and al, 2011).

Based on the aforesaid empirical studies, we decided to take an unbiased position:

H2: There is a mitigated relation (+/-) between the outreach and the competition.

\subsection{Regulation}

The commercialization of microfinance gives a big deal of importance to the regulation of the MFIs. In this respect, MFIs provide their services to less than 5\% of their potential clients due to the insufficient resources to be highlighted in order to satisfy the needs of that market coming mainly from the financial backers. In this subject, several MFIs wish to develop their activities by calling for commercial sources of financing, particularly deposit mobilization, the access to external sources of financing and so the enhancement of their financial results which makes the resort to the regulation a necessity (CGAP, 1996).

In this context, in a study employing the average loan size as an index of the inclusion of the poor applied in MFIs of Latin America, Christen (2001) found important differences in loans size between regulated and unregulated MFIs, with a big deal of importance in loans size given to regulated ones.

Furthermore, Cull and al (2009) show that the regulation exhibits a negative impact on the outreach. Merslan and Strôm (2009), as well, show that the regulation gives the right to mobilize the savings and so give access to important source of financing. Consequently, this, not only, gives the possibility to increase the number of clients, but also, the average loan size, which is originally similar to a social mission drift. However, Morduch (1999) and Arun and al (2005) foresees that the regulation of microfinance provides a favorable environment for the improvement of the outreach.

The impact of the regulation is, then, difficult to foresee because a more strict regulation may imply less free actions and consequently smaller benefits. On another hand, the regulation can guarantee to clients an equitable behavior. This may lead to a better financial performance. Therefore, we took a neutral position concerning the impact of the rules on the inclusion of the poor.

\section{H3: there is a mitigated relation (+/-) between the outreach and the regulation.}

\subsection{Data source and samples}

\section{Empirical study}

The source of our data is Microfinance Information eXchange (MIX). The final sample is formed of 96 African MFI, composed of 31 NGOs and 65 financial MFIs (cooperatives ${ }^{1}$, non-banking financial institutions and banks). The MFIs chosen for our sample possesses diamond levels of 4 and $5^{2}$ (Tchakoute, 2010).

\footnotetext{
${ }^{1}$ We classify the cooperatives among the financial companies since these institutions give the opportunity of having financial services of savings, credit, insurance or transfers.

${ }^{2}$ Diamond system indicating the availability and quality of the data obtained from MFIs.carried out by MIX in order to classify the IMF according to the transparency and the quality of information: The IMF of level 4 are those which reveal relative information with the outreach, with the impact of the activities of microfinance on the target customers. Their
} 
We chose the African MFIs in our study since they are significantly less effective than those of other regions of the world (Lafourcade and al, 2006; Cull and al, 2007; Gutierrez-Nieto and al, 2009).

Table 2 summarizes the composition of the sample in each region and the MFIs' legal status.

\section{"Insert table 2"}

\subsection{Model and measurement of the variables}

In order to answer the question raised in our study, seeking to estimate the impact of the MFIs' commercialization on the social outreach; we estimate a linear regression model. The equation of our estimation is of the following form:

$$
\begin{aligned}
& P_{i j t}=c+\text { OSS }_{i j t}+\mathrm{REG}_{j i t}+\text { Lerner }_{i j t}+W B_{i j t}+I N D I V_{i j t}+F O R J U R_{i j t}+A G E_{i j t}+ \\
& S I Z E_{i j t}+\varepsilon_{i j t}
\end{aligned}
$$

Our dependent variable $\left(\mathbf{P}_{i j t}\right)$ measures the MFIs' outreach i.e. the capacity of the MFI to reach the poor by tow measures. First of all, we assess the outreach of the MFI by the degree of poverty of served clients measured by the ratio:

$$
d i=\frac{\text { Average Loan Balance per Borrower }}{\text { GNI per Capita }}
$$

The average loan balance $\left(\mathbf{d}_{i j t}\right)$ is the indicator used in our study in order to measure the degree of the social outreach of the MFIs (Bhatt and Tang, 2001; Schreiner, 2002; Cull and al, 2007; Mersland and Strôm, 2009). The adjustment in GNI per citizen enables the normalization of the average loan size since it is in terms of local currency and offers an adjustment of the total wealth of the country in question. We resort, in this context, to the classification according to the criteria of Micro banking Bulletin (Africa) and we use two groups of population: $1^{\text {st }}$ group: di<20\% representing the poorest clients and the 2 nd group: di $>20 \%$ standing for the rich clients (Montalieu, 2002; Morduch J, 2006).

The second measure of the outreach of MFIs is the percentage of women borrowers $\left(\boldsymbol{W} \boldsymbol{B}_{\boldsymbol{i j t}}\right)$. $1^{\text {st }}$ group: WB: di<20\% representing the poorest women and the $2^{\text {nd }}$ group: WB: di $>20 \%$ standing for richer women. In fact, the social outreach of the MFIs may be associated with the intense targeting of women in priority (Dowala and Barua, 2006; Guérin, 2006).

Concerning the explicative variables, we use three major measurements commonly employed in literatures dealing with MFIs' commercialization (Olivares-Polanco, 2005; Cull and al, 2009; Hermes and al, 2009; Hermes and al, 2011).

We chose three measurements for this approach, at the very beginning; we calculate the financial viability of the MFIs by the operational self-sufficiency $\left(\boldsymbol{O S} \boldsymbol{S}_{\boldsymbol{i j t}}\right)$. The second factor is the competition; such a variable is measured by Lerner index $\left(\boldsymbol{L e r n e r}_{\boldsymbol{i j t}}\right)$. The third factor is the MFIs' regulation $\left(\mathbf{R E G}_{\boldsymbol{j i t}}\right)$ measured by a dummy variable equal to the value of 1 if the MFI is regulated and the value of 0 if otherwise.

We added specific variables to the MFI allowing us to explain the impact of the commercialization of the MFIs on the social outreach. (INDIV $\left.\boldsymbol{V}_{\boldsymbol{i j t}}\right)$ is a dummy variable that takes the value of 1 if the MFI adopt the approach of the individual loans and null if otherwise (Mersland and Strôm, 2009 and Tchakoute, 2010); (FORJUR $\boldsymbol{R}_{\boldsymbol{i j t}}$ ) is measured by a dummy variable taking the value of 1 if the legal form is NGO and 0 if otherwise; the specific variables of the MFI indicates its age $\left(\ddot{\boldsymbol{A}} \boldsymbol{G} \boldsymbol{E}_{i t}\right)$ (number of years since its creation) and its size $\left(\boldsymbol{S I Z \boldsymbol { E } _ { i t } )}\right.$ measured by the logarithm of the MFI's total assets (Cull and al, 2009). Table 3 describes the set of variables as well as the source of each and every one.

\subsection{Estimation method}

\section{"Insert table 3"}

Our empirical study consists of assessing the impact of the commercialization factors on the average loan size and on the percentage of women borrowers in our sample. We estimate such relationship using the regression technique with OLS on STATA in order to study the impact of the MFIs' commercialization on the average loan size and the percentage of women borrowers per group of served population. For that purpose, we use two samples: the first one reunite the group of MFIs that offer their services to the poorest clients (group 1: $\mathrm{N}=128$ for MFI having di<20\%). This sample will enable us to figure out the impact of the MFIs transformation on the category of the poorest borrowers with a much higher risk of insolvability and who are probably about to be excluded after the transformation of the MFI. The second sample concerns the group of MFIs serving less poor and rich clients (group 2: $\mathrm{N}=256$ for MFIs having di $>20 \%$ ). Clients belonging to this group have a lower risk of insolvability of those of the first group. The difference between both groups allows us to figure out the circumstances where the poorest clients can keep their accounts within the MFIs after their transformation. The estimation based on the OLS method requires the realization of the homoskedasticity test which consists of the

financial statements (assessment and income statement) are audited and certified. Five diamonds represent data as with four diamonds plus rating and other benchmarking assessments. 
study of the behavior of the errors (residues) issued from the model. In order to identify an eventual heteroscedasticity of the errors we use the White test.

\subsection{Descriptive statistics}

\section{Empirical results}

Table 4 exhibits the descriptive statistics of the continuous explicative variables as well as the dependant variables. The analysis of the data of table 4 indicates that the average of the ratio (di) for the aggregate sample is located between $20 \%$ and $149 \%$ and woman represent more than the half of the population served with an average of $59,12 \%$. In other words, the served clientele is of an average level of poverty and we may deduce that the MFIs of the sample are viable $(117 \%>100 \%)$. The average of Lerner index is 0.3 which suggest that the MFIs in our data base are confronted with average levels of competition.

\section{"Insert table 4"}

Concerning the evolution of the variables of the competition measured by Lerner index over time, we simplified these evolutions of the aggregate sample represented respectively in figure 1 and 2 . These figures exhibit the temporal evolution of Lerner index respectively for the MFIs serving the poorest borrowers $(\mathrm{di}<20 \%)$ and the MFIs serving the rich ones (di>20\%).

Figure 1 shows that the evolution of Lerner Index for the first group $(\mathrm{di}<20 \%)$ tend to a situation of accentuated competition by the end of 2008. This situation is expected in this category of MFIs since it is mainly composed of non-profit-making NGOs that cannot make profits enabling them to compete with other juridical forms. The situation is totally inversed in the second group of MFIs ( $\mathrm{di}>20 \%$ ) (figure 2) which evolves to a monopole situation during the study period. This group is mainly composed of MFIs with commercial vocation.

\section{"Insert figure 1 and 2"}

\subsection{Main empirical results}

Our main purpose in this paper is to study the impact of the transformation of the MFIs on their own capacity to present services to the poor and improve the welfare of woman. We estimate our model thanks to the STATA software.

The results of table 5 show that the regression models are significant as it is indicated by the coefficient $\left(\boldsymbol{R}^{2}\right)$. The first and the second colmns consists of estimating the impact of the commercialization's factors on the capacity to include the poor through the OLS method on STATA, in order to study the impact of commercialization of the MFIs on the average loans size per group of served clientele: The first Group 1: $\mathrm{N}=128$ for MFIs having di $<20 \%$, and the second Group 2: $\mathrm{N}=256$ for MFIs having di $>20 \%$. The decrease is considered as an indication of a better integration of the poor (Cull and al, 2007). Whereas, the third and the forth columns indicate the impact of commercialization on targeting women borrowers by groups. The increase is considered as an indication of a better integration of the women (Guérin, 2006)

\section{"Insert table 5"}

The first column of table 5 consist of assessing the impact of commercialization on the social outreach of the MFIs which distribute the credits to the poorest clients $(\mathrm{di}<20 \%)$. This table underlines the existence of mission drift's signs carried out by the viability of the MFIs. We can, then, deduct that the MFIs that are financially autonomous tend to increase the average size of their loans and prefer to grant them to rich clients. In fact, in order to ensure their survival in an increasingly competitive market, the MFIs must reduce their expensive operations and increase their efficiency which suggests that the pursuit of the social goal and the financial autonomy are two contradictory objectives. This point of view corroborates our assumption $\mathrm{H} 1$ and explains the results of Hartarska (2005) and Mersland and Strôm (2009).

However, regulation and competition seems to be in favor of the reduction of the average loan size in the first group and by doing so the struggle for the poor's right of the inclusion in the sector of microfinance. In this context, it turns out that the results of the first group (di<20\%) are similar to those of Morduch (1999) and Arun and al (2005). Concerning the positive impact of the competition on the social outreach, such a result was provided by Motta (2004), Cull and al (2007; 2009) and Hermes and al (2011) which suggest that the competition pushes micro-credits toward the poorest markets through the diversification of the provided products, the reduction of the monopole's annuities and the rates of interests of the granted loans as well, which may lead to the enhancement of the social outreach.

Concerning the second column (di $>20 \%$ ), we note that there are signs of mission drift carried out by viability and regulation on the MFIs of this group. Thus, regulation and viability are unfavorable for the social outreach in MFIs serving rich clients (di>20\%). As a matter of fact, regulation tends to strengthen practices of commercial nature regardless the social dimension of the activities of microfinance. This can carry along the interruption of the multiplication of non-profit MFIs as well as presenting many constraints for the intervention in rural locations and within agricultural sectors and so it will lead to a change of the composition of new clients 
in addition to existing ones, as well as a reorientation from poor zones to rich ones thus the occurrence of a mission drift is stressed (Cull and al, 2007).

Regarding the impact of commercialization on the percentage of women borrowers of the MFIs which distribute the credits to the poorest women (WB: di<20\%), results in the third column of the table 5 indicate that the MFIs that are financially autonomous tend to exclude the women borrowers. In fact, MFIs consider that this category of population generate very high costs and are not able to pay off their debts. This result can be justified by the fact that investors tend to put their funds to MFIs which provide to rich clients which can afford to pay back higher loans. And in this process they lend increasingly fewer loans to women borrowers and hence deviate from their mission of serving the poor clients. (A. Nawaz, 2010). This point of view corroborates our assumption H1 and explains the results of Hartarska (2005) and Mersland and Strôm (2009), and it's the same one as that found for group 2 (WB: di $>20 \%$ ).

Contrariwise, we find that competition favor the inclusion of the poor and the women borrowers for the two groups (WB: di<20\% and WB: di $>20 \%$ ). Indeed, the accelerating commercialization of microfinance, and consequently of competition, stimulate product diversification and technology improvements in information which have potential to significantly increase access to cheaper and better microfinance services particularly for women. (Mayoux, 2004)

Finally, we also find that the regulation of MFIs condemn the inclusion of the poorest clients, but also the inclusion of female. Consequently, we deduce that the poorest women in the transformed MFIs are the most likely to be excluded, mainly where reimbursement is the most important consideration in the MFI. Therefore, the excluded poor women may be made even more vulnerable throughout market regulation by imposing stiff restrictions which can prevent their inclusion. (Mayoux, 2004)

During the analysis of the quality of the credit portfolio for both groups of borrowers, we find out that for those who received small size credits $(\mathrm{di}<20 \%)$ and for women borrowers in this group, the relation between the variable measuring the refund time line (Par30) and the average size of the loans is positive and significant. Whereas, this relation is significantly negative for the group of clients that are granted loans with bigger size $(\mathrm{di}>20 \%)$. This justifies that the category of population of the first group, and particularly women recorded refunding delays more important than those of the second group as the size of the loans increases. This result is similar to that of Armendariz and Morduch (2010).

Concerning the legal form, the results show that the reference legal form (NGO) is capable of realizing the outreach of the poorest clients $(\mathrm{di}<20 \%)$ and also the poorest women. However, it does not belong to the set of MFIs of the second group (di>20\%). This shows that the MFIs collecting deposits (Cooperatives and private companies) exhibit levels of social outreach significantly inferior than those of the NGO if the size of the loans is considered as a comparison basis. This result is similar to those of Hartarska (2005) and Mersland and Strôm (2009), however they contrast with those of Tchakoute (2010) and they are explained by the costs required by the transformation of the NGOs into a commercial entity and the constraint of collecting deposits.

The increase of the MFIs' size is also favorable for targeting the poorest borrowers (group 1) since it leads to the decrease of the size of the loans granted to the clients. This result is similar to that of Vanroose (2008) and Ahlin and al (2010). However, the variables of the size and the age of the MFIs are positively and significantly associated to the average loan size of the second group (di $>20 \%$ ), but negatively associated with the percentage of women borrower. This result shows that the maturity of the MFIs is accompanied with an increase of the size of the granted loans and consequently, an increase of the size of the total asset of the MFI. We conclude, therefore, that for the group (di>20\%), the size and the age of the MFIs are in favor with the mission drift of these MFIs.

The positive and significant coefficient between $(\mathrm{di}<20 \%)$ and $(\mathrm{di}>20 \%)$ with the approach of individual credit, as well as the negative relation between (WB: $\mathrm{di}<20 \%$ ) with this methodology provides certain proofs of mission drift in time. This proves that, whatever the targeted clientele is, the size of the credit as part of the approach of individual credit increases in time. These results are similar to those of Amendariz de Aghion and Morduch (2005), Ghatak and Guinnane (1999), Thorp, Stewart and Heyer (2005) and Baland and al (2007, 2009). In fact, as part of individual loans, the responsibility of refunding lies only on the borrower himself, whereas in a group loan, the responsibility will be between the members of group.

\section{Conclusion}

There is fear that the commercialization of the MFIs leads to a "mission drift" as the MFI seeks more profitable markets generating less costs at the expense of the poorest clients and particularly of the women. As part of this paper, we evaluated the impact of the factors of commercialization on the average loan size as well as the percentage of women borrowers in order to clarify the debate between the MFIs' commercialization and their social outreach. We used these data in 96 MFI operating in 22 African countries during the period from 2005 to 2008 and provided descriptive and econometric proofs based on OLS on STATA in order to study the 
impact of the commercialization of the MFIs on the average size of the loans per group of served population (group 1: (di<20\%) and group 2: (di>20\%)).

The results indicate that competition favor targeting the poorest and increase significantly access to cheaper and better microfinance services particularly for women. Whereas, viability is in favor of the mission drift of the MFIs no matter what the category of served clientele is. In fact, autonomous MFIs tend to increase the average size of their loans and prefer to grant them to rich clients. We also find that regulated MFIs lend increasingly fewer loans to women borrowers and hence deviate from their mission of serving the poor clients.

We suggest studying in future researches procedures to be adopted by the MFIs to improve their outreach and to insure the welfare of served clients.

\section{Bibliography}

[1] Arun. T. Hulme. D. Matin. I and Rutherford. S (2005)., "Finance for the Poor: the way forward? ". Chapter in Finance and Development - Surveys of Theory. Evidence and Policy edited by Christopher J. Green. Colin H. Kirkpatrick and Victor Murinde. Edward Elgar.

[2] Bikker. J. and K. Haaf (2002). "Measures of Competition in the Banking Industry: A Review of the Literature". Economic and Financial Modelling 9: 53-98

[3] Christen. R. P..Rhyne.E.. Vogel. R. C.. and McKean. C. (1995).. "Maximizing the outreach of microenterprise finance: An analysis of successful microfinance programs". (USAID Program and Operations Assessment Report No. 10). Washington. DC.

[4] Christen. R.P. (2001)., "Commercialization and mission drift. The transformation of microfinance in Latin America".(CGAP Occasional Paper No. 5). Washington. DC.

[5] Cull, R., Demirguc-Kunt, A. and Morduch, J., (2007), "Financial performance and outreach: A global analysis of lending microbanks", Economic Journal, 117, 2007, F107-F133.

[6] Cull, R., Demirgüç-Kunt, A. and Morduch, J., (2009), "Microfinance Tradeoffs: Regulation, Competition, and Financing", The World Bank Development Research Group Finance and Private Sector Team October 2009. No 8.Consultative Group to Assist the Poor (CGAP), The World Bank, Washington D.C.

[7] Fernàndez deGuevara. J., J. Maudos and F. Pèrez (2007)., "Integration and Competition in the European Financial Markets". Journal of International Money and Finance 26: 26-45.

[8] Florent Bédécarrats and Reynaldo Marconi, (2009), "L'influence De La Régulation Sur La Contribution De La Microfinance Au Développement : Le Cas De La Bolivie," Revue Tiers-Monde, Armand Colin, vol. 0(1), pages 71-90.

[9] Hartarska, V. (2005), "Governance and Performance of Microfinance Institutions in Central and Eastern Europe and the Newly Independent States". World Development, 33(10), pp. 1627-1643.

[10] Hermes. N., Robert L.. and Aljar M. (2009). "Outreach and efficiency of microfinance institutions". Centre for International Banking. Insurance and Finance WorkingPaper.

[11] Hermes. N.. Assefa. E. and Meesters. A. (2011)., "Competition and Performance of Microfinance Institutions". Department of Economics.Econometrics and Finance Faculty of Economics and Business University of Groningen.the Netherlands.

[12] Hishigsuren, G. (2007). "Evaluating mission drift in microfinance: Lessons for programs with social mission". Evaluation Review, 31(3), 205-259.

[13] Ly.P (2012), "The effect of ownership in NGOS' commercialventures", Annals of Public and Cooperative Economics, 83:2 2012, pp. $159-179$.

[14] Maudos. J. and J. FernPndez de Guevara (2004). "Factors Explaining the Interest Margin in the Banking Sectors of the European Union". Journal of Banking and Finance 28: 2259-2281.

[15] Mayoux, L., (2004), "Women's Empowerment and Participation in Micro-finance: Evidence, Issues and Ways forward". In Mayoux, L. (ed.), Sustainable Learning for Women's Empowerment: Ways Forward in Micro-Finance, New Dehli, Hardbound.

[16] Meyer. R.L. (2002)."Track Record of Financial Institutions in Assisting the Poor in Asia" ADB Institute Research Paper.No 49. December 2002.

[17] MiX and CGAP. (2011)., "Afrique Subsaharienne 2010 Benchmarking et Analyse Du Secteur De La Microfinance". Rapport du Microfinance Information Exchange (MIX) et du Groupe consultatif d'assistance aux pauvres (CGAP). Avril 2011.

[18] Morduch. J (1999), "The Microfinance Promise". Journal of Economic Literature.Vol. 37.No.4. pp.1569-1614.

[19] Olivares-Polanco. F., (2005)., "Commercializing Microfinance and Deepening Outreach: Empirical Evidence from Latin America". Journal of Microfinance 7: 47-69.

[20] Seibel D. H. and Felloni F. (2003), "Commercialisation de la microfinance : une expérience basée sur le modèle Grameen Bank aux Philippines", Epargne Sans Frontière, TFD, n73, Décembre. 


\section{ANNEXES}

Table 1: Results of the cost function

\begin{tabular}{|c|c|}
\hline explicative variables & $\operatorname{Ln}(\mathrm{TC})$ \\
\hline (Lny) & $0.7195 * * *$ \\
\hline & $(\mathbf{0 . 0 0 0 )}$ \\
\hline$(\operatorname{Lny})^{2}$ & 0.0120 \\
\hline & $(0.239)$ \\
\hline$\left(\mathbf{L n w}_{\mathbf{1}}\right)$ & 0.3288 \\
\hline & $(0.062)$ \\
\hline$\left(\mathbf{L n w}_{1}\right)^{2}$ & $\begin{array}{r}-0.0188 \\
(0.148)\end{array}$ \\
\hline$\left(\mathbf{L n w}_{2}\right)$ & $-0.3978 * * *$ \\
\hline & $\begin{array}{r}(0.038) \\
0.0719 * * *\end{array}$ \\
\hline$\left.(\mathrm{D}) \mathrm{w}_{2}\right)$ & $(\mathbf{0 . 0 0 0})$ \\
\hline Trend & 0.0334 \\
\hline & (0.340) \\
\hline Trend $^{2}$ & $\begin{array}{r}-0.000038 \\
(0.650)\end{array}$ \\
\hline Lny*Lnw & 0.00285 \\
\hline & $(0.892)$ \\
\hline $\operatorname{Lny}^{*} \operatorname{Lnw}_{2}$ & 0.00787 \\
\hline & $(0.720)$ \\
\hline $\operatorname{Lnw}_{1} * \mathbf{L n w}_{2}$ & $\mathbf{0 . 0 5 0 8}^{* * *}$ \\
\hline & $(\mathbf{0 . 0 2 5})$ \\
\hline (Lny*trend) & 0.000031 \\
\hline & $(0.947)$ \\
\hline$\left(\mathrm{Lnw}_{1} *\right.$ trend $)$ & $-0.00107 * * *$ \\
\hline & $(0.001)$ \\
\hline$\left(\mathrm{Lnw}_{2} *\right.$ trend $)$ & 0.00037 \\
\hline & $(0.195)$ \\
\hline Constant & -0.74661 \\
\hline & $(0.838)$ \\
\hline Observations & 384 \\
\hline R-Square & $56,70 \%$ \\
\hline Number of MFIs & 96 \\
\hline
\end{tabular}

Our models are estimated by the appraiser simple panel.

$*, * *, * * *$ Significant at $10 \%, 5 \%$ and $1 \%$, respectively.

The coefficient is indicated by the numbers above, the probability is in brackets.

Ln (TC): $\log$ of the total cost, $\operatorname{Ln}(\mathrm{y}): \log$ of total output, $\operatorname{Ln}\left(\mathrm{y}^{2}\right): \log$ of squared output, $\operatorname{Ln}\left(\mathrm{w}_{1}\right)$ : $\log$ of labor cost, $\left(\mathrm{Lnw}_{1}\right)^{2}: \log$ of squared labor costs, Ln $\left(\mathrm{w}_{2}\right)$ : Log of labor cost $\left(\mathrm{Lnw}_{2}\right)^{2}:$ Log of squared labor costs; trend: time trend; trend $^{2}$ : squared time trend; $\operatorname{LnY} * \operatorname{Lnw}_{1}: \log$ of output $* \log$ of total labor costs; LNY* $\operatorname{Lnw}_{2}: \log$ of output * Log of total capital cost; $\mathrm{Lnw}_{1} * \mathrm{Lnw}_{2}: \log$ of labor costs $* \log$ of capital cost; trend $* \operatorname{LnY}: \log$ of total output * time trend, trend * $\operatorname{Lnw}_{1}: \log$ of labor costs $*$ time trend, trend $* \operatorname{Lnw}_{2}: \log$ of capital cost $*$ time trend.

Table 2: Regional distribution and legal status of MFIs

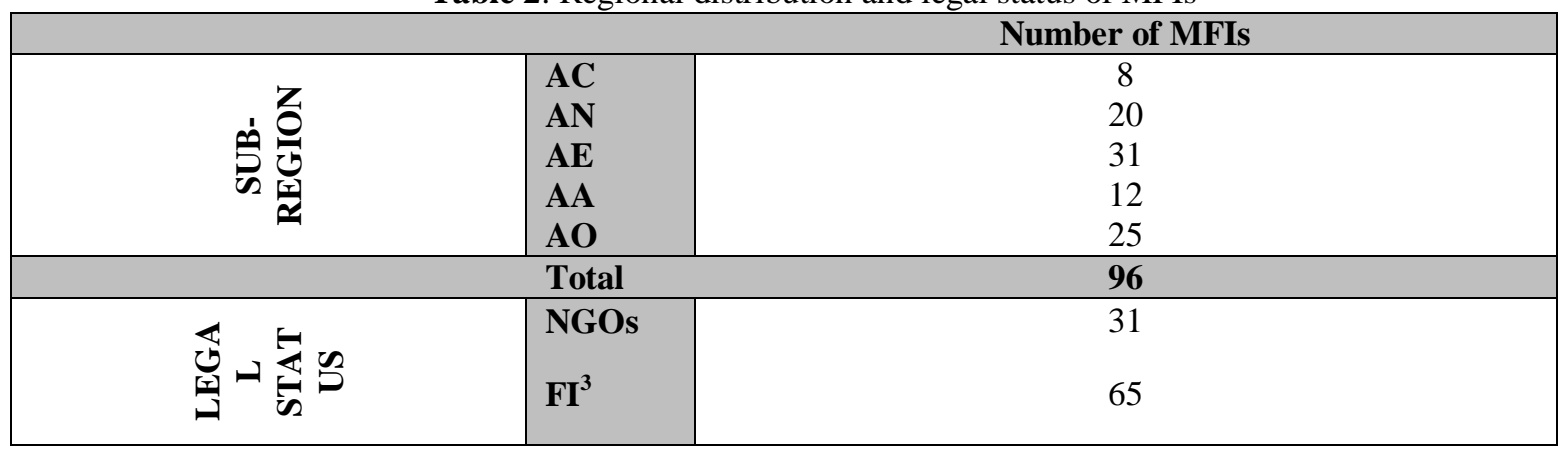

${ }^{3}$ Financial institutions 
Table 3: Operationalization and definition of variables

\begin{tabular}{|c|c|c|}
\hline Variables & Measures & Source \\
\hline \multicolumn{3}{|c|}{ dependent variables } \\
\hline di & $\begin{array}{l}\mathbf{d i}=\frac{\text { average loan balance per borrower }}{\text { GNI per capita }} \text {; This ratio measures the degree of poverty of } \\
\text { clients served by MFIs. }\end{array}$ & $\mathrm{MIX}^{4}$ \\
\hline \multirow[t]{2}{*}{ WB } & Percentage of women borrowers. & MIX \\
\hline & Explicative variables: commercialization factors & \\
\hline OSS & $\begin{array}{l}\text { Operational self-sufficiency ratio: } \\
\text { OSS }=\text { [Financial Revenue / (Financial expenses }+ \text { operating expenses }+ \\
\text { provision for doubtful debts)], this ratio measures the ability of the MFI to cover } \\
\text { its costs from its income holdings. }\end{array}$ & MIX \\
\hline REG & Dummy variable: 1 if the MFI is regulated by a regulation organism, 0 otherwise. & MIX \\
\hline \multirow[t]{2}{*}{ Lerner } & $\begin{array}{l}\text { Lerner Index }: \boldsymbol{L}=\frac{\mathbf{P}-\mathbf{M C}}{\mathbf{P}} \\
\text { (The market price minus marginal cost, adjusted by the market price) }\end{array}$ & MIX \\
\hline & Explicative variables: other factors & \\
\hline FORJUR & Dummy variable: 1 if the MFI is an NGO, 0 otherwise. & MIX \\
\hline INDIV & Dummy variable: 1 if the MFI adopt individual contracts, 0 otherwise. & ratingfund $^{5}$ \\
\hline AGE & Number of years since the creation of the IMF. & MIX \\
\hline SIZE & Logarithm of total assets of the MFI. & MIX \\
\hline
\end{tabular}

Table 4: Descriptive statistics of continuous variables in the aggregate sample

\begin{tabular}{|c|ll|llll|}
\cline { 2 - 7 } \multicolumn{1}{c|}{} & di & WB & OSS & Lerner & SIZE & Age \\
\hline Average & 73,06 & 59,12 & 117,11 & 0,30 & 8,93 & 11,04 \\
Median & 41,67 & 59,48 & 112,45 & 0,28 & 8,67 & 9,00 \\
MAX & 615,85 & 153,96 & 521,87 & 0.99 & 13,80 & 58,00 \\
MIN & 0,00 & 0,00 & 3,99 & 0,01 & 4,94 & 4,00 \\
\hline Observation & $\mathbf{3 8 4}$ & $\mathbf{3 8 4}$ & $\mathbf{3 8 4}$ & $\mathbf{3 8 4}$ & $\mathbf{3 8 4}$ & $\mathbf{3 8 4}$ \\
\hline
\end{tabular}

Figure 1: Evolution of the estimated average of "Lerner index" over time (Group 1: di <20\%)

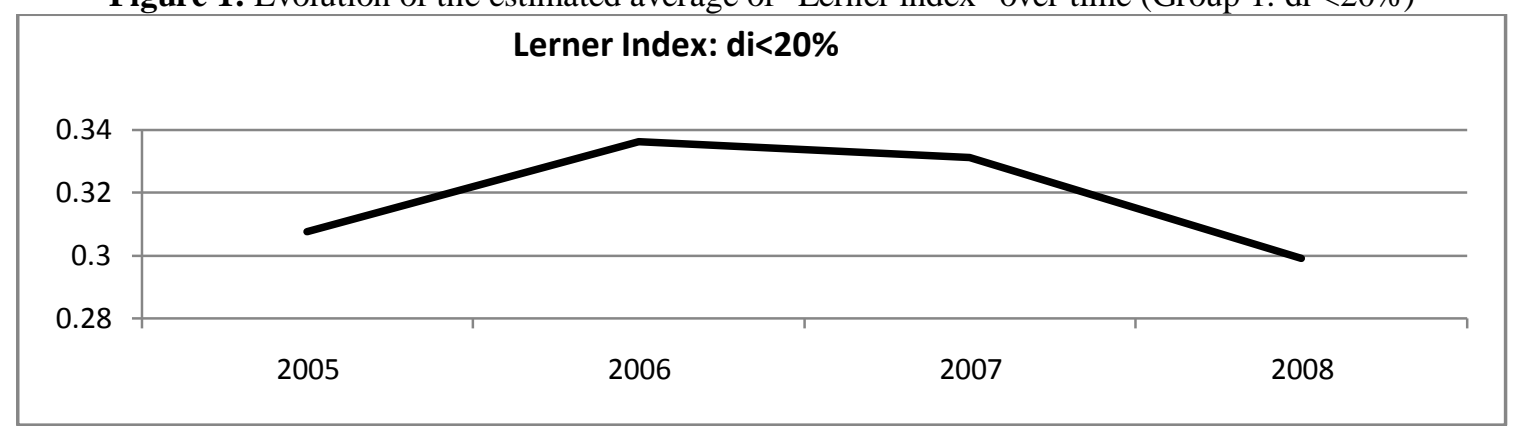

\footnotetext{
${ }^{4}$ MIX : Mixmarket, "Microfinance Information eXchange », www.themix.org.

${ }^{5}$ Notation ratio available on (www.ratingfund.org).
} 
Figure 2: Evolution of the estimated average of "Lerner index" over time (Group 2: di > 20\%)

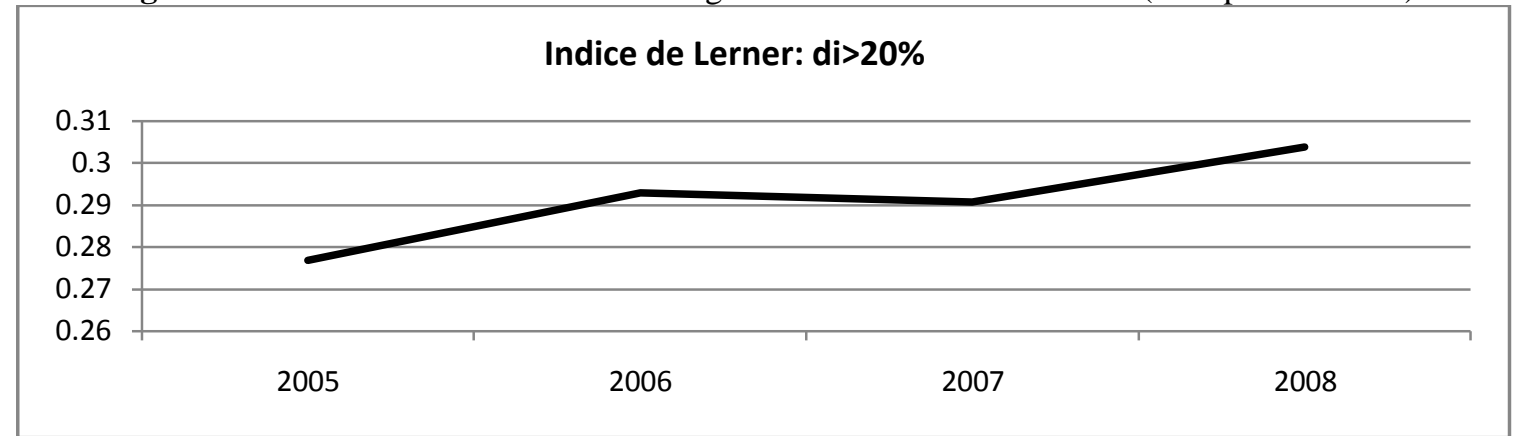

Table 5: Regression results by category of clients served (OLS)

\begin{tabular}{|c|c|c|c|c|}
\hline Explicative variables & $\operatorname{di}($ gr1 $)<20 \%{ }^{1}$ & $\operatorname{di}(\operatorname{gr} 2)>20 \%{ }^{3}$ & WB $($ gr1 $)<20 \%{ }^{1}$ & WB $\left(\right.$ gr2) $>20 \%{ }^{2}$ \\
\hline OSS & $9.0107 * * *$ & $9.859 * *$ & $-0.0429 *$ & $-0.0874 * * *$ \\
\hline & (0.007) & $(0.034)$ & $(0.052)$ & (0.001) \\
\hline & $-8.450 * * *$ & $16.934 * * *$ & $2.589 *$ & $-3.529 *$ \\
\hline REG & $(0.0054)$ & $(0.000)$ & $(0.058)$ & $(0.045)$ \\
\hline & $-8.834 * * *$ & $-19.453 * * *$ & $13.70 * * *$ & $11.816 * * *$ \\
\hline Lerner & $(0.005)$ & (0.019) & $(0.024)$ & $(0.002)$ \\
\hline Dor 20 & $6.9621 * * *$ & $-9.459 * * *$ & $-0.0164 * * * *$ & -0.4064 \\
\hline Par30 & $(0.000)$ & $(0.041)$ & $(0.0009)$ & $(0.745)$ \\
\hline INDIV & $6.923 * * *$ & $20.065 * * *$ & $-14.783 * * *$ & 0.683 \\
\hline & $(0.016)$ & $(0.016)$ & $(0.005)$ & $(0.855)$ \\
\hline FOP WUD & $-8.779 * * * *$ & $21.834 * * *$ & $15.646 * * * *$ & 6.983 \\
\hline FURJUR & $(0.008)$ & $(0.0312)$ & $(0.014)$ & $(0.156)$ \\
\hline $\mathrm{CF}$ & 6.5677 & $4.4512 * * *$ & $-0.1491 * * *$ & 0.0018 \\
\hline AGE & $(0.257)$ & $(0.001)$ & $(\mathbf{0 . 0 3 0})$ & $(0.995)$ \\
\hline SIZF & $-9.6387 * * * *$ & $21.923 * * *$ & 2.315 & $-2.689 * * * *$ \\
\hline S1RE & $(0.001)$ & $(\mathbf{0 . 0 0 0 )}$ & $(0.079)$ & (0.009) \\
\hline constant & $\begin{array}{c}8.938 \\
(0.051)\end{array}$ & $\begin{array}{c}158.026 * * * \\
(0.000)\end{array}$ & $\begin{array}{c}101.90 * * * * \\
(0.000)\end{array}$ & $\begin{array}{c}89.55 * * * \\
(0.000)\end{array}$ \\
\hline $\mathbf{N}$ & 128 & 256 & 128 & 256 \\
\hline $\mathbf{R}^{2}$ & $77.88 \%$ & $76.77 \%$ & $69.83 \%$ & $88.27 \%$ \\
\hline
\end{tabular}

the sample (group 1) is estimated by OLS with correction for heteroscedasticity using the White test in STATA; ${ }^{2}$ the sample (group 2) is estimated by OLS with correction for heteroscedasticity using the White test in STATA. $*, * *, * * *$ Significant at $10 \%, 5 \%$ and $1 \%$, respectively.

The coefficient is indicated by the numbers above, the probability is in brackets. 